\title{
Papers
}

\section{An evaluation of three commercial kits for use as screening methods for the detection of leptospiral antibodies in the UK}

\author{
W J Zochowski, M F Palmer, T J Coleman
}

\begin{abstract}
Aims-To compare three commercial screening tests-the PanBio leptospiral IgM enzyme linked immunosorbent assay (ELISA), the Biolisa leptospiral IgM ELISA, and the indirect haemagglutination assay (IHA)-with the microscopic agglutination test (MAT) and two "in house" ELISAsurease and horseradish peroxidase (HRP)for the detection of leptospiral antibodies in a local UK and Eire population.

Method-Two hundred sera submitted for a differential diagnosis of leptospirosis were tested by all methods. A further 142 sera from patients with antibodies to toxoplasma, Epstein-Barr virus (EBV), hepatitis A virus, rheumatoid factor, Borrelia burgdorferi, Mycoplasma pneumoniae, syphilis, cytomegalovirus, and $Q$ fever were tested for crossreactivity.

Results-Compared with the MAT, sensitivity and specificity were found to be: PanBio, 90\%/94\%; Biolisa with sorbent, $100 \% / 85 \%$; and IHA, $54 \% / 95 \%$. Seven of 200 trial sera gave false negative results with PanBio; 14 of 200 trial sera gave false positive results with Biolisa with sorbent, as did a further 25 of the 142 sera tested for potential crossreactivity. Two of 142 sera gave crossreactions with PanBio and IHA (one each).

Conclusions-The degree of false positivity seen with the Biolisa suggests that the recommended positive value of $\geqslant 26 \mathrm{Eu} / \mathrm{ml}$ should be reassessed using pools of sera from local populations. When the cut off value was reassessed, using a value of $\geqslant 40 \mathrm{Eu} / \mathrm{ml}$, a sensitivity and specificity of $96 \%$ and $94 \%$, respectively, was achieved. Even the modified Biolisa appears to be over sensitive and to show a high degree of non-specificity. The IHA, although specific $(95 \%)$, lacked sensitivity in this study. The PanBio appeared to be the most suitable as a screening test for leptospiral IgM in the UK, although it would be advisable for all positive test results to be confirmed by a different enzyme immunoassay and the MAT. (F Clin Pathol 2001;54:25-30)
\end{abstract}

Keywords: leptospirosis; enzyme linked immunosorbent assay; indirect haemagglutination assay
Leptospirosis is a zoonotic disease with a worldwide distribution. In the UK, the main animal reservoirs are cattle and rodents, and humans become infected through contact with contaminated animal urine, tissues, or water. Leptospiral serovars can be classified by traditional methods as being pathogenic Leptospira interrogans or nonpathogenic leptospires included in the Leptospira biflexa group. The current taxonomy of leptospires using DNA techniques places serovars into 17 species within the genus Leptospira. ${ }^{1}$ In the UK, infections caused by the serovars icterohaemorrhagiae and hardjo predominate and are most frequently associated with contact with rats or cattle urine, respectively.

The clinical presentation of leptospirosis in humans is variable, and can range from a mild flu-like illness to a severe illness with jaundice, meningitis, renal failure, and occasionally death. In general, diagnosis is based initially upon clinical suspicion, confirmed later by the laboratory-usually by the detection of specific antibody. Using the most sensitive methods currently available, leptospiral $\operatorname{IgM}$ is detectable from about the fifth day after the onset of symptoms. ${ }^{2}$ Screening methods for leptospiral antibodies have included complement fixation (CF), ${ }^{3}$ slide agglutination, ${ }^{4}$ indirect haemagglutination (IHA), ${ }^{5-7}$ microcapsule agglutination tests, ${ }^{8}$ and enzyme linked immunosorbent assay (ELISA) for IgM antibodies, $^{29-14}$ with confirmation by the microscopic agglutination test (MAT). The latter is not suitable for routine laboratories because the maintenance of live strains of leptospires, a potential biohazard, and the complexities of the test and its interpretation require considerable expertise.

Traditionally, screening for leptospirosis has been carried out at local level in the UK by the $\mathrm{CF}$ test, using antigen supplied by the Leptospira Reference Unit (LRU). This ceased to be available in 1997. Laboratories continued screening using commercial ELISA and IHA assays. These kits are produced outside the UK and none had been evaluated, using a local population pool, against the strains of leptospires predominating in the UK. An increasing number of sera, positive by these tests and sent
Accepted for publication 20 July 2000 
to the LRU for assessment, were not being confirmed by "in house" enzyme immunoassay (EIA) or MAT. An assessment of the kits in common usage was considered appropriate at this time.

An ideal screening test should have the robustness and simple methodology to be undertaken by all laboratories, and be suitable for use as a single or multiple assay. Sensitivity should be high but not at the expense of acceptable specificity. Reliable results are required to enable prompt antibiotic treatment to be initiated.

The aim of our study was to compare three commercial kits commonly chosen for the detection of leptospiral antibodies. Our study was designed to assess sera similar to those encountered in the routine laboratory. In house ELISA methods of the LRU and the MAT were included as screening and confirmatory tests.

\section{Materials and methods \\ SERA}

Two hundred sera were chosen from those submitted to the LRU, between 1996 and 1997, by laboratories located in the UK and Eire, from patients in whom the differential diagnosis included leptospirosis. One hundred sera giving positive ELISA results were selected with titres ranging from $1 / 80$ to 1/2560. MAT titres, where positive, ranged from $1 / 40$ to $1 / 5120$. One hundred sera were negative by MAT and ELISA. Sera were chosen on the basis of titre rather than duration of illness. In addition, 142 sera were included as recent/acute cases of toxoplasma (25), Epstein-Barr virus (EBV) (19), hepatitis A virus (HAV) (21), Borrelia burgdorferi (15), Mycoplasma pneumoniae (13), syphilis (13), cytomegalovirus (CMV) (14), or Q fever (8), and those with rheumatoid factor (14) detected in their serum. These sera were included to assess the possibility of crossreactivity with the assay systems under investigation. All sera were randomised and coded before testing.

All sera (342) were tested using the following methods: urease ELISA, horseradish peroxidase (HRP) ELISA (both in house ELISAs), MAT, IHA (MRL Diagnostics, Cypress, California, USA), and two commercial ELISA kits-PanBio (PanBio, Queensland, Australia) and Biolisa (BIOS $\mathrm{GmbH}$, Müenchen, Germany).

A further 40 sera were selected at random from those obtained from an ongoing prospective study of zoonotic disease in farm workers. These sera had previously been found negative for the presence of leptospiral antibodies at the LRU and were tested by Biolisa only.

UREASE AND HRP ELISAS

Antigen

A heat extracted antigen derived from a culture of $L$ interrogans serovar hardjo strain Hardjoprajitno ${ }^{9}$ was used for both methods. Aliquots of $100 \mu \mathrm{l} /$ well were air dried on to flat bottomed polystyrene ELISA plates (Corning, New York, USA).

\section{Urease ELISA}

The urease ELISA was carried out as described previously by Zochowski et al. ${ }^{14}$ Briefly, after thorough washing of antigen coated plates with phosphate buffered saline (PBS) plus Tween (PBST) (PBS ( $\mathrm{pH} \mathrm{7.2)} \mathrm{containing} \mathrm{0.05 \%} \mathrm{vol/}$ vol Tween 20$), 100 \mu$ l volumes of patients' sera were serially diluted from $1 / 20$ to $1 / 2560$ in diluent buffer (PBST containing 0.25\% w/v bovine albumin fraction $\mathrm{V}$ and $0.01 \%$ sodium azide). Plates were sealed and incubated at $37^{\circ} \mathrm{C}$ for 60 minutes. Positive and negative controls were included on each plate. After aspiration and washing, $100 \mu \mathrm{l}$ volumes of urease conjugated antihuman IgM (Sigma, Poole, Dorset, UK) at optimal dilution were added to all wells. Plates were again covered and incubated at $37^{\circ} \mathrm{C}$ for 60 minutes. After incubation, plates were aspirated and washed with PBST, with a final wash with distilled water. Aliquots $(100 \mu \mathrm{l})$ of the substratechlorophenol red in $0.2 \mathrm{mM}$ EDTA (ethylenediaminetetraacetic acid, disodium salt) at $\mathrm{pH} 4.8$-were added to all wells. Plates were covered and incubated at $37^{\circ} \mathrm{C}$ for 60 minutes. Plates were read using a plate reader with a $492 \mathrm{~nm}$ filter to quantify the resultant colour change from yellow (negative) to magenta (positive). In accordance with our standard protocol, an optical density (OD) of 0.5 was used as the cut off value. Values of $0.0-0.5$ were positive, whereas values $>0.5$ were negative. A titre of $1 / 80$ or greater was considered positive for the presence of leptospiral antibody.

\section{HRP ELISA}

This ELISA was carried out according to the current protocol used at the LRU. After washing antigen coated plates with PBST, serial dilutions of patients' sera from $1 / 20$ to $1 / 2560$ were made in diluent buffer (PBST containing $1.0 \%$ Marvel (Premier Beverages, Stafford, $\mathrm{UK})$ ) in $100 \mu \mathrm{l}$ volumes. Plates were sealed and incubated at $37^{\circ} \mathrm{C}$ for 60 minutes. After aspiration and washing, $100 \mu \mathrm{l}$ volumes of peroxidase conjugated antihuman IgM (Sigma) at optimal dilution were added to all wells. Plates were again sealed and incubated at $37^{\circ} \mathrm{C}$ for 60 minutes. After aspiration and washing, $100 \mu \mathrm{l}$ of chromogenic substrate ABTS (2,2 azino-di-3-ethylbenzthiazoline sulphonate) (Sigma) in $0.05 \mathrm{M}$ citric acid buffer at $\mathrm{pH} 4.0$, containing $5 \mu \mathrm{l}$ hydrogen peroxide $(30 \% \mathrm{wt} / \mathrm{vol}) / 20 \mathrm{ml}$, was added to all wells. Plates were incubated at room temperature for 15 minutes. The OD was read at $405 \mathrm{~nm}$. A cut off OD of 0.18 had been determined by calculating the mean OD of 40 negative sera $+3 \mathrm{SD}$. An OD above this value was considered positive. Titres of $1 / 80$ or greater were considered positive for the presence of leptospiral antibody.

Both EIA assays were included to validate data obtained from the recently introduced HRP ELISA. 
COMMERCIAL ASSAYS

All assays were performed as specified by the manufacturers' information supplied with each kit and, therefore, only brief details are given below.

\section{PanBio}

Trial sera and controls were diluted $1 / 100$ in serum diluent, and $100 \mu \mathrm{l}$ of each was added to antigen coated microELISA wells. Plates were covered and incubated at $37^{\circ} \mathrm{C}$ for 20 minutes. After aspiration and washing with wash buffer, $100 \mu \mathrm{l}$ volumes of HRP conjugated antihuman IgM were added to all wells. Plates were again sealed and incubated at $37^{\circ} \mathrm{C}$ for 20 minutes. After aspiration and washing, $100 \mu \mathrm{l}$ TMB substrate (3,3',5,5'-tetramethylbenzidine and hydrogen peroxide in an organic base) was added to all wells. Plates were incubated for 10 minutes at room temperature and then $100 \mu \mathrm{l}$ of "stop solution" (1 M phosphoric acid) was added to all wells. The OD of each well was read at $405 \mathrm{~nm}$. PanBio units were calculated and interpreted as instructed: < 10 PanBio units, negative; 10-20 PanBio units, low positive; > 20 PanBio units, positive.

\section{Biolisa}

The kit insert suggests that sera should be pretreated with "sorbent" containing Biolisa Reiter-Spirochete and IgG absorbent "if desired" before assaying, to improve specificity. Because sorbent is required as an addition to the kit, it is possible that its availability may be overlooked. Therefore, two series of assays were performed: one where sera were pretreated with sorbent for 15 minutes at a dilution of $1 / 10$, then diluted to $1 / 500$ in diluent buffer as directed; the other where sera were diluted in diluent buffer (1/500) only. For each series, $100 \mu \mathrm{l}$ of diluted sera and controls was added to wells of a microELISA plate. Plates were sealed and incubated at $37^{\circ} \mathrm{C}$ for 30 minutes. After aspiration and washing, $100 \mu \mathrm{l}$ of alkaline phosphatase conjugated antihuman IgM was added to all wells. Plates were sealed and again incubated at $37^{\circ} \mathrm{C}$ for 30 minutes. After aspiration and washing, $100 \mu \mathrm{l}$ of chromogenic substrate, $p$-nitrophenyl phosphate, was added to all wells. Plates were sealed and incubated at $37^{\circ} \mathrm{C}$ for 30 minutes. After incubation, $50 \mu \mathrm{l}$ stop solution $(2 \mathrm{M} \mathrm{NaOH})$ was added to all wells. The OD of each well was read at $405 \mathrm{~nm}$. Arbitrary units $(\mathrm{Eu} / \mathrm{ml})$ were calculated as instructed. Interpretation: $<20 \mathrm{Eu} / \mathrm{ml}$, negative; 20-25 Eu/ml, borderline; and $>25 \mathrm{Eu} / \mathrm{ml}$, positive.

\section{IHA}

Trial sera were diluted $1 / 50$ in PBS and, for each, $50 \mu \mathrm{l}$ of diluted serum was mixed with $25 \mu l$ of either control or test cells in two wells of a $\mathrm{U}$ bottomed plate. Positive and negative controls were included on each plate. Plates were shaken mechanically for 15 to 30 seconds, and incubated at room temperature for 60 minutes. Haemagglutination patterns were read independently by two trained laboratory technical staff, on a scale of 0 to $4+$. Interpret- ation: no agglutination, negative; $\geqslant 1+$ agglutination, positive.

\section{$M A T$}

The MAT ${ }^{15}{ }^{16}$ was performed using a battery of antigens. The antigens used were reference strains from the following serogroups, with selected serovars (given in brackets) combined into pools based on serogroups. Australis (australis, bajan, bratislava); Autumnalis (autumnalis, bangkinang, bim, bulgarica); Ballum (ballum, guangdong, castellonis); Bataviae (argentiniensis, bataviae, brasiliensis, claytoni); Canicola (bafani, benjamini, bindjei, canicola); Celledoni (anhoa, celledoni, mengding, whitcombi); Cynopteri (cynopteri, tingomariensis); Grippotyphosa (canalzonae, grippotyphosa, huanuco); Hebdomadis (hebdomadis, jules, longnan); Icterohaemorrhagiae (birkini, copenhageni, dakota, icterohaemorrhagiae); Javanica (ceylonica, coxi, fluminense, javanica); Mini (beye, georgia, hekou, mini); Pomona (kunming, mozdok, pomona, proechimys); Pyrogenes (princestown, pyrogenes, robinsoni); Sejroe hardjo; Sejroe saxkoebing; Sejroe sejroe; Tarassovi (navet, rama, tarassovi); L biflexa serogroup Semaranga serovar patoc was also included.

Table 1 Positivity score for the 100 positive and 100 negative trial sera tested by each assay system compared with the microscopic agglutination test (MAT)

\begin{tabular}{lll}
\hline Assay system & $\begin{array}{l}\text { Positive sera } \\
(n=100)\end{array}$ & $\begin{array}{l}\text { Negative sera } \\
(n=100)\end{array}$
\end{tabular}

PanBio

PanBio+/MAT+

PanBio+/MAT -

PanBio-/MAT+

PanBio-/MAT-

Biolisa with sorbent

Biolisa+/MAT+

Biolisa+/MAT-

Biolisa-/MAT+

Biolisa-/MAT-

Biolisa without sorbent

Biolisa+/MAT+

Biolisa+/MAT-

Biolisa-/MAT+

Biolisa-/MAT-

Indirect haemagglutination assay $(\mathrm{IHA})$

IHA+/MAT+

IHA+/MAT -

IHA-/MAT+

IHA-/MAT-

In house ELISAs

In house ELISA+/MAT+

In house ELISA+/MAT-

In house ELISA-/MAT+

In house ELISA-/MAT-

Biolisa with sorbent

Biolisa borderline/MAT+

Biolisa borderline/MAT-

Biolisa without sorbent

Biolisa borderline/MAT-

Borderline results not scored.

ELISA, enzyme linked immunosorbent assay.

Table 2 Sensitivity and specificity of IgM screening tests compared with the microscopic agglutination test (MAT)

\begin{tabular}{lcl}
\hline Screening test & Sensitivity (\%) & Specificity (\%) \\
\hline PanBio & 90 & 94 \\
Biolisa with sorbent & 100 & 85 \\
Biolisa without sorbent & 100 & 82 \\
IHA & 54 & 95 \\
In house ELISAs & 96 & 93
\end{tabular}

ELISA, enzyme linked immunosorbent assay; IHA, indirect haemagglutination assay. 
Table 3 Sera tested for possible non-specific crossreactivity and positive results

\begin{tabular}{|c|c|c|c|c|c|c|}
\hline $\begin{array}{l}\text { Sera demonstrating } \\
\text { antibodies to }\end{array}$ & No. tested & $\begin{array}{l}\text { In house ELISAs } \\
\text { and } M A T\end{array}$ & PanBio & $\begin{array}{l}\text { Biolisa with } \\
\text { sorbent }\end{array}$ & $\begin{array}{l}\text { Biolisa without } \\
\text { sorbent }\end{array}$ & $I H A$ \\
\hline Toxoplasma & 25 & 0 & 0 & 1 & 3 & 0 \\
\hline EBV & 19 & 0 & 0 & 2 & 5 & 0 \\
\hline HAV & 21 & 0 & 0 & 6 & 8 & 0 \\
\hline Rheumatoid factor & 14 & 0 & 0 & 1 & 2 & 0 \\
\hline Borrelia burgdorferi & 15 & 0 & 0 & 0 & 2 & 0 \\
\hline Mycoplasma & 13 & 0 & 0 & 0 & 3 & 1 \\
\hline Syphilis & 13 & 0 & 0 & 1 & 2 & 0 \\
\hline CMV & 14 & 0 & 1 & 0 & 0 & 0 \\
\hline Q fever & 8 & 0 & 0 & 0 & 0 & 0 \\
\hline Total & 142 & & & & & \\
\hline $\begin{array}{l}\text { Positivity } \\
\text { (\% of total tested) }\end{array}$ & & $\begin{array}{r}0 / 142 \\
(0 \%)\end{array}$ & $\begin{array}{l}1 / 142 \\
(0.7 \%)\end{array}$ & $\begin{array}{r}11 / 142^{\star} \\
(7.7 \%)\end{array}$ & $\begin{array}{r}25 / 142^{\star \star} \\
(17.6 \%)\end{array}$ & $\begin{array}{c}1 / 142 \\
(0.7 \%)\end{array}$ \\
\hline
\end{tabular}
rect haemagglutination assay; MAT, microscopic agglutination test.

Serial twofold dilutions of patient serum were made in $0.01 \mathrm{M}$ PBS ( $\mathrm{pH} 7.2$ ) starting from $1 / 20$. Leptospiral antigens were formalised and an equal volume was added to serum dilutions and incubated overnight at room temperature in a damp chamber. The titre was taken as the highest dilution giving $50 \%$ agglutination of leptospires. Titres of $1 / 40$ or above were considered positive.

\section{Results}

Table 1 gives the positivity scores for the 100 positive and 100 negative sera tested by all assay systems. Table 2 gives the sensitivity and specificity ${ }^{17}$ of each test compared with the MAT.

\section{NON-SPECIFIC CROSSREACTIVITY}

Table 3 shows the results of testing for non-specific crossreactions. No crossreactivity was noted with the in house ELISAs or with the MAT. The commercial kits showed varying degrees of crossreactivity. Overall, Biolisa with sorbent gave 11 of $142(7.7 \%)$ false positive results, with a further $10(7.0 \%)$ borderline results, giving a combined false positivity of $14.7 \%$ (21 of 142 ). Biolisa without pretreatment of the sera with sorbent gave 25 of 142 $(17.6 \%)$ false positives and a further nine of $142(6.3 \%)$ borderline results, giving a combined false positivity of 34 of $142(23.9 \%)$. The IHA and PanBio each gave one of $142(0.7 \%)$ false positive results.

Table 4 Trial sera positive by Biolisa alone tested for the presence of antibodies with the potential for crossreactivity

\begin{tabular}{lcc}
\hline Sera tested for antibodies to (type of test) & $\begin{array}{l}\text { Biolisa with } \\
\text { sorbent positive }\end{array}$ & $\begin{array}{l}\text { Biolisa without } \\
\text { sorbent positive }\end{array}$ \\
\hline Toxoplasma (latex aggln) & 3 & 3 \\
HAV (EIA) & 7 & 8 \\
Rheumatoid factor (latex aggln) & 1 & 2 \\
Borrelia burgdorferi (EIA) & 0 & 1 \\
Mycoplasma (CFT) & $1^{\star}$ & 1 \\
Syphilis (VDRL/TPHA) & 0 & 0 \\
CMV (latex aggln) & 6 & 8 \\
Q fever (CFT) & $0^{\star}$ & $0^{\star \star}$ \\
Number of sera tested & 10 & 13 \\
\hline
\end{tabular}

EBV testing was not performed.

${ }^{\star}$ A further two sera showed anticomplementary activity.

${ }^{\star \star}$ A further three sera showed anticomplementary activity.

These results indicate that multiple positive results were seen with some sera.

EIA, enzyme immunoassay; CFT, complement fixation test; CMV, cytomegalovirus; HAV, hepatitis A virus; TPHA, Treponema pallidum haemagglutination test; VDRL, Venereal Disease Reference Laboratory.
Table 5 Effect of raising the cut off level on Biolisa with sorbent results

\begin{tabular}{lll}
\hline Cut off in Eu/ml & Sensitivity (\%) & Specificity (\%) \\
\hline$\geqslant 26$ & 99 & 85 \\
$\geqslant 30$ & 96 & 90 \\
$\geqslant 40$ & 94 & 96 \\
$\geqslant 50$ & 88 & 96 \\
\hline
\end{tabular}

BIOLISA POSITIVE SERA

Of the 16 sera in the initial batch of 200 sera tested that were found to be positive by Biolisa alone, giving either positive or borderline results, 13 were available for further testing. These sera were tested using the routine tests used by Hereford PHL, for the presence of antibodies to those agents defined in the non-specific crossreactivity study above, to determine whether the presence of such antibodies might have had an influence on the Biolisa results. The data, shown in table 4 , indicated that individual sera can be positive for more than one agent. High rates of positivity for antibodies to HAV (70\%), CMV (60\%), and toxoplasma (30\%) were demonstrated. These were also associated with positive Biolisa results in the investigation of non-specific crossreactivity described above.

\section{BIOLISA CUT OFF VALUES}

The information provided with this kit recommends a positive value of $\geqslant 26 \mathrm{Eu} / \mathrm{ml}$, with borderline results for values between 20 and $25 \mathrm{Eu} / \mathrm{ml}$. These values were based on a study of the population of Münich. During the study many low positive/borderline results were seen with this assay alone. Combined with our own observations of this assay it was felt that the cut off might not be appropriate for the UK and Eire. Therefore, sensitivity and specificity were recalculated for the Biolisa plus sorbent only, with differing cut off values and no borderline values used (table 5).

\section{ZOONOSIS STUDY SERA}

To assess the performance of Biolisa on sera known to be serologically negative for leptospirosis, a further 40 sera were selected at random from those obtained from an ongoing prospective study of zoonotic disease in farm workers. MAT and ELISA at the LRU had previously found these sera negative on two consecutive occasions for the presence of lept- 
Table 6 Results for seven patients initially found positive by Biolisa, from 40 sera selected at random from a zoonosis trial

\begin{tabular}{|c|c|c|c|c|c|c|c|c|c|}
\hline \multirow[b]{3}{*}{ Screening test } & \multicolumn{9}{|c|}{ Year of sampling } \\
\hline & \multicolumn{3}{|c|}{$1993 / 4$} & \multicolumn{3}{|c|}{$1995 / 6$} & \multicolumn{3}{|c|}{1998} \\
\hline & Pos & $B / L$ & $\mathrm{Neg}$ & Pos & $B / L$ & Neg & Pos & $B / L$ & $\mathrm{Neg}$ \\
\hline In house ELISA & 0 & - & 7 & 0 & - & 7 & 0 & - & 7 \\
\hline PanBio & 0 & - & 7 & 0 & - & 7 & 0 & - & 7 \\
\hline MAT & 0 & - & 7 & 0 & - & 7 & 0 & - & 7 \\
\hline IHA & 0 & - & 7 & 0 & - & 7 & 0 & - & 7 \\
\hline Biolisa with sorbent & 3 & 3 & 1 & 2 & 4 & 1 & 2 & 3 & 2 \\
\hline Biolisa without sorbent & 5 & 2 & 0 & 5 & 2 & 0 & 4 & 1 & 2 \\
\hline
\end{tabular}

Initial and follow up sera for these seven patients were retested by all methods.

ELISA, enzyme linked immunosorbent assay; IHA, indirect haemagglutination; MAT, microscopic agglutination test.

ospiral antibodies. The sera were tested with Biolisa only and seven of 40 were found positive or borderline. These seven sera and further sera taken from the same patients one and three years later were retested using all methods. Table 6 shows the results. The in house ELISAs, MAT, PanBio, and IHA all gave negative results.

\section{Discussion}

From the results presented in table 2, it can be seen that the in house ELISAs and PanBio tests compare favourably in both sensitivity and specificity. The Biolisa shows a higher sensitivity, but it appears to be at the expense of specificity. This is most apparent when the sorbent is not used. Although the kit protocol recommends pretreatment with sorbentBiolisa Reiter-spirochaete and IgG absorbent-it is not included with the kit. From the results obtained during this assessment it can be seen that pretreatment with sorbent did indeed improve the specificity from $82 \%$ to $85 \%$ and, therefore, we would recommend that it should be supplied with the kit. IHA was previously found to have a sensitivity of $92-100 \%$ and a specificity of $94-95 \% .{ }^{6}{ }^{7}$ In our study, a sensitivity of only $54 \%$ was seen, with a comparable specificity of $95 \%$.

The PanBio kit appeared to produce false negative results with seven sera. Two were from confirmed cases of leptospirosis with no further samples included in this trial. One was a convalescent sample taken five months after onset, an earlier sample was positive by PanBio. These trial sera were positive by all other tests. The remaining sera were from a patient with confirmed infection. The samples were taken between 12 and 47 days after onset of symptoms. All samples were negative by PanBio and IHA. Conversely, the Biolisa, both with and without sorbent, gave a high proportion of false positive results. This kit uses a positive cut off value of $\geqslant 26 \mathrm{Eu} / \mathrm{ml}$, with a borderline value between 20 and $25 \mathrm{Eu} / \mathrm{ml}$. The manufacturer recommends that borderline positive results should be further investigated, with confirmatory tests based on a different methodology. When a value of $40 \mathrm{Eu} /$ $\mathrm{ml}$ is used to determine positive results, a sensitivity and specificity of $94 \%$ and $96 \%$, respectively, is obtained. At $\geqslant 50 \mathrm{Eu} / \mathrm{ml}$, although the specificity remains the same $(96 \%)$, the sensitivity falls to $88 \%$. Analysis of those samples that fall below the cut off values suggests that, at $\geqslant 30 \mathrm{Eu} / \mathrm{ml}$, three sera (one serum from a serologically confirmed case of leptospirosis and two sera with equivocal serology but no follow up sera) would have been missed. At $\geqslant 40 \mathrm{Eu} / \mathrm{ml}$, five sera (two from serologically confirmed cases and three from patients who gave equivocal serology but had no follow up sera) would have been missed. At $\geqslant 50 \mathrm{Eu} / \mathrm{ml}$, 10 sera (six from serologically confirmed cases and four from patients who gave equivocal serology with no follow up sera) would have been missed. Thus, using a UK and Eire based population study, a suggested positive cut off of $40 \mathrm{Eu} / \mathrm{ml}$ or above may be more appropriate, although even at this value false positives occur and false negativity may be introduced. All positive results obtained with this test should be confirmed by other methodology, including MAT. In addition, further sera should be examined from suspected clinical cases of leptospirosis giving negative Biolisa results.

From the results presented in table 3, demonstrating degrees of crossreactivity, it can be seen that, of the commercial kits, Biolisa gave the highest positivity rate $(14.7 \%$ when sera were pretreated with sorbent, $23.9 \%$ without sorbent). Crossreactivity was noted with all the groups tested, with the exception of $Q$ fever. A borderline result was noted with one CMV serum. Those groups demonstrating the highest rates with Biolisa with sorbent were HAV (28.6\%) and EBV (9.5\%). With the PanBio and IHA kits, crossreactivity was noted with CMV (one serum) and mycoplasma (one serum), respectively. Both these sera were also seen to be borderline positive by Biolisa. The degree of crossreactivity with PanBio was similar to that observed by Australian workers. ${ }^{2}$ The high crossreactivity seen with Biolisa suggests that several of the trial sera found to be positive with a negative MAT might also have been demonstrating crossreactivity. Therefore, trial sera that were positive or borderline by Biolisa alone were also tested for antibodies to those groups used in the crossreactivity study. From table 4 it can be seen that potential crossreactive antibodies were present in these sera. HAV, giving the highest positivity rate, was also suggested as a major contributor to non-specificity in the crossreactivity study. Therefore, this might suggest that some of the positive reactions seen in the initial 200 sera screened with the Biolisa were non-specific. Of the 13 sera tested, none was from a case of leptospirosis found previously or subsequently.

All three commercial kits are capable of detecting antibodies produced in response to many leptospiral serovars, ${ }^{2} 7$ which was also confirmed by our study (eight serovars). Although technically all the kits were suitable for use in routine laboratories, the extremes in sensitivity seen with the Biolisa and IHA kits suggest that the PanBio is the most robust kit, comparing favourably with the in house ELISAs and giving few false positive results. The occasional false negative result seen with PanBio indicates that at least one further serum sample from suspected clinical cases should be examined before a diagnosis of leptospirosis is 
excluded. With all commercial screening tests it is strongly advised that positive determinations should be referred to a specialised reference laboratory, to be confirmed by a different EIA and the MAT.

We thank Mrs E Hughes for her technical assistance and the laboratories that kindly provided the sera for the crossreactivity study.

1 Brenner DJ, Kaufmann AF, Sulzer KR, et al. Further determination of DNA relatedness between serogroups and serovars in the family Leptospiraceae with a proposal for Leptospira alexanderi sp. nov. and four new Leptospira genomaspecies. Int f Syst Bacteriol 1999;49:839-58.

2 Winslow WE, Merry DJ, Pirc ML, et al. Evaluation of a commercial enzyme-linked immunosorbent assay for detection of immunoglobulin $\mathrm{M}$ antibody in diagnosis of human leptospiral infection. 7 Clin Microbiol 1997;35:1938-42.

3 Turner LH. Leptospirosis II serology. Trans R Soc Trop Med Turner LH. Leptospirosis

4 Galton MM, Powers DK, Hall AM, et al. A rapid microscopic-slide screening test for the serodiagnosis of leptospirosis. Am f Vet Res 1958;19:505-12.

5 Sulzer CR, Jones WL. Evaluation of a haemagglutination test for human leptospirosis. Appl Microbiol 1973;26:655-7.

6 Sulzer CR, Glosser JW, Rogers F, et al. Evaluation of an indirect haemagglutination test for the diagnosis of human leptospirosis. 7 Clin Microbiol 1975;2:218-21.

7 Levett PN, Whittington CU. Evaluation of the indirect haemagglutination assay for diagnosis of acute leptospirosis. $\mathcal{F}$ Clin Microbiol 1998;36:11-14.
8 Arimitsu Y, Kmety E, Ananyina Y, et al. Evaluation of the one-point microcapsule agglutination test for the diagnosis of leptospirosis. Bull World Health Organ 1994;72: 395-9.

9 Terpstra WJ, Ligthart GS, Schoone GJ. Serodiagnosis of human leptospirosis by enzyme linked immunosorbent assay (ELISA). Zentralbl Bakteriol Hyg 1 Abt Orig A 14 247:400-5.

10 Terpstra WJ, Ligthart GS, Schoone GJ. ELISA for the detection of specific IgM and IgG in human leptospirosis. $\mathcal{F}$ Gen Microbiol 1985;131:377-85.

11 Adler B, Murphy AM, Locarnini SA, et al. Detection of specific antileptospiral immunoglobulins $\mathrm{M}$ and $\mathrm{G}$ in human serum by solid phase enzyme-linked assay. $\mathcal{F}$ Clin Microbiol 1980;11:452-7.

12 Pappas MG, Ballou WR, Gray MR, et al. Rapid serodiagnosis of leptospirosis using the IgM-specific dot-ELISA: comparison with the microscopic agglutination test. Am $\mathcal{F}$ Trop Med Hyg 1985;34:346-54.

13 Woodward MJ, Swallow C, Kitching A, et al. Leptospira hardjo serodiagnosis: a comparison of MAT, ELISA and Immunocomb. Vet Rec 1997;141:603-4.

14 Zochowski WJ, Waitkins SA, Palmer MF. The use of ELISA in the diagnosis of human leptospirosis. Israel fournal of Veterinary Medicine 1987;43:330-9.

15 Wolff JW. The laboratory diagnosis of leptospirosis. Springfield, Illinois: Charles C Thomas, 1954.

16 Palmer MF, Waitkins SA, Wanyangu SW. A comparison of live and formalised leptospiral microscopic agglutination test. Zentralbl Bakteriol Hyg A 1987;A256:151-9.

17 Barker DJP, Bennett FJ. Making observations and counting diseases. In: Practical epidemiology, 3rd ed. Edinburgh: Churchill Livingstone, 1982:12-26.

\section{PATHOLOGY INTERACTIVE 2000}

Do you know ... . ?

Pathology Interactive Volume 2 now offers:

Up to three CPD credits per review article

1 credit for reading the article and completing the associated questions

1 credit for additional reading, following up references

1 credit for making notes, identifying learning outcome or identifying further learning needs

CPD credits for working on articles outside your specialty

\section{Pathology Interactive Volume 2 Issue 1 includes articles in:}

Microbiology

Histopathology

Molecular pathology

\section{Further issues in 2000 will cover further articles in these specialties, plus:}

Chemical pathology

Haematology

Immunology

Including case study and picture quiz formats

Pathology Interactive 2000 Volume 2, 4 issues (March, June, September, December) ISSN 1466 5743. Accredited by the Royal College of Pathologists

Subscription rate: $£ 75+$ VAT personal ${ }^{\star}, £ 150$ +VAT institutional (multiuser rate on application to the publisher).

Send orders to: BMJ Publishing Group, Journals Marketing Dept, PO Box 299, London WC1H 9TD, UK; fax credit card orders to: +44 (0)20 7383 6402; call subscriptions hotline +44(0)20 7383 6270; email orders to: subscriptions@bmjgroup.com

*ACP members receive Pathology Interactive with their copy of Fournal of Clinical Pathology, as a membership benefit. 